\title{
Metabolism of a Plant Wax Paraffin ( $n$-Nonacosane) by a Soil Bacterium (Micrococcus cerificans)
}

\author{
By L. HANKIN AND P. E. KOLATTUKUDY \\ Department of Biochemistry, The Connecticut Agricultural Experiment \\ Station, New Haven, Connecticut, U.S.A.
}

(Accepted for publication 29 October 1967)

\begin{abstract}
SUMMARY
Long-chain paraffins, such as nonacosane, reach the soil from plants and are degraded by micro-organisms. The ability of one soil organism, Micrococcus cerificans, to grow on cabbage paraffin ( $n$-nonacosane) was studied. Unlike the pattern seen with hexadecane, waxy esters were not produced when nonacosane was the sole carbon source, but esters were formed when a cooxidation technique of $\left[{ }^{14} \mathrm{C}\right] n$-nonacosane with hexadecane was employed. The alcohol and acid portions of the radioactive esters formed were primarily of chain length $\mathrm{C}_{16}, \mathrm{C}_{17}$ and $\mathrm{C}_{18}$; neither nonacosanol nor nonacosanoic acid were detected. Thus the nonacosanol and nonacosanoic acid which might have been produced from $n$-nonacosane must have been oxidized to shorterchain compounds which in turn were incorporated into waxy esters as well as other lipids.
\end{abstract}

\section{INTRODUCTION}

Large amounts of paraffins reach the soil from plants (Stevenson, I966) and much of this is degraded by micro-organisms present in the soil. These plant paraffins are generally found to have carbon chain-lengths of $\mathrm{C}_{27}-\mathrm{C}_{35}$, with $\mathrm{C}_{29}$ (nonacosane) one of the most abundant (Silva-Fernandes, Baker \& Martin, 1964). Little is known about bacterial utilization of these plant paraffins although the bacterial degradation of petroleum paraffins $\left(\mathrm{C}_{12}\right.$ to $\left.\mathrm{C}_{18}\right)$ has been studied extensively (McKenna \& Kallio, 1965). Many species of micro-organisms can grow on paraffins as a sole carbon source and attempts are being made to produce edible microbial proteins from petroleum (Champagnat, 1964). Longer paraffins $\left(\mathrm{C}_{20}-\mathrm{C}_{34}\right)$ are known to be utilized by microorganisms (ZoBell, I950) and they can also be utilized by animals (Kolattukudy \& Hankin, I966).

It has been shown (Stevenson, Finnerty \& Kallio, I962; Stewart et al. I959; Stewart $\&$ Kallio, 1959) that Micrococcus cerificans produces waxy esters from medium chainlength paraffins; the alcohol portion of the ester has the same chain length as the substrate paraffin but the acid portion varies. If this metabolic pattern applies to the verylong-chain plant paraffins then very-long-chain alcohols would be produced. The demonstration that such long-chain alcohols possess androgenic activity (Levin, 1963) raises the possibility that the intestinal flora may produce physiologically active compounds from long-chain paraffins present in the food supply (Kuksis, 1964; SilvaFernandes et al. 1964).

In the present report, the metabolic fate of $n$-nonacosane (from cabbage wax) in $M$. cerificans, a soil organism, is discussed. 


\section{METHODS}

Organism. Micrococcus cerificans was maintained as a stock culture on agar slants prepared with $3.1 \%$ of nutrient agar supplemented with $0.5 \%$ each of yeast extract and Casamino acids (Difco), and subcultured weekly. The organism was kindly provided by Dr R. E. Kallio, University of Illinois, Urbana.

Media. The basal mineral medium contained per litre of distilled water: $\left(\mathrm{NH}_{4}\right)_{2} \mathrm{SO}_{4}$, 2 g.; $\mathrm{KH}_{2} \mathrm{PO}_{4}, 4$ g.; $\mathrm{Na}_{2} \mathrm{HPO}_{4}, 6$ g. $; \mathrm{FeSO}_{4} \cdot 7 \mathrm{H}_{2} \mathrm{O}$, I mg.; $\mathrm{MgSO}_{4}, 200$ mg.; $\mathrm{CaCl}_{2}$, I mg.; $\mathrm{H}_{3} \mathrm{BO}_{3}$, Io $\mu \mathrm{g}$.; $\mathrm{MnSO}_{4}$, Io $\mu \mathrm{g}$.; $\mathrm{ZnSO}_{4}, 70 \mu \mathrm{g}$.; $\mathrm{CuSO}_{4}, 50 \mu \mathrm{g}$; $\mathrm{MoO}_{3}$, $10 \mu \mathrm{g}$.; calcium pantothenate, $200 \mathrm{mg}$. $\mathrm{pH} 7 \cdot 5$.

Test media (except where indicated) were prepared by adding sterile (autoclaved) paraffins $(0 \cdot 5-1 \cdot 0 \%$ except for radioactive material) to sterile basal mineral medium. To emulsify the hydrocarbon the medium was then subjected to ultrasonic disintegration (Biosonic II, Will Corporation) at $90 \%$ of maximum output for Io min. The ultrasonic disintegration step was omitted when $n$-hexadecane was the substrate.

Growth studies. In comparative growth tests of different substrates, the same amount of inoculum was placed in each flask. At least $27 \times 10^{6}$ bacteria $/ \mathrm{ml}$. were used in each test. Growth was measured by a direct microscopic method (American Public Health Assoc., 1948) after staining the bacteria with a solution of crystal violet. For all tests, the organism was grown in shake culture in a water bath at $30^{\circ}$. When radioactive $n$-nonacosane was used, in addition to shaking, sterile air was bubbled through the incubation mixture to remove radioactive $\mathrm{CO}_{2}$.

Preparation of substrates and standards. Paraffins other than $n$-nonacosane were a gift from Dr B. J. Humphrey (Humphrey Chemical Co., North Haven, Conn., U.S.A.). Both radioactive and non-radioactive $n$-nonacosane was obtained from the cuticular wax of Brassica oleracea as previously described (Kolattukudy, I965; Kolattukudy \& Hankin, I966). Standard long-chain esters used for gas chromatographic analysis were prepared from stearyl alcohol and acyl chlorides with pyridine as catalyst.

Gas chromatography. Gas chromatographic analyses were made on a Perkin Elmer 810 gas chromatograph with a flame ionization detector. The columns used have previously been described (Kolattukudy, 1967). Radioactive material emanating from the column was measured with a radioactivity monitor (Barber-Coleman).

Isolation and identification of lipids. Total lipids were extracted from the incubation mixture by the method of Folch, Lees \& Sloane-Stanley (I957) with a 2+ I (v/v) mixture of chloroform and methanol. After concentration, the extract was placed on a silica gel column (Kolattukudy, 1967; Kolattukudy \& Hankin, 1966). The components were eluted successively with hexane, benzene and methanol (containing $10 \%$ of acetic acid). Hexane eluted the paraffins, benzene the esters, and methanol the polar lipids (glycerides, phospholipids). Lipid classes were identified by thin-layer chromatography (Mangold, 1965). Fatty acids from glycerides and phospholipids were isolated after saponification with ethanolic $\mathrm{KOH}$ under nitrogen. Methyl esters were prepared with $\mathrm{BF}_{3}$ as catalyst. The waxy esters were isolated from the benzene eluate of the silica gel columns by thin-layer chromatography on silica gel $\mathrm{G}$ with benzene as the developing solvent. The ester fraction was saponified with ethanolic $\mathrm{KOH}$ under nitrogen, and the alcohol and acid fractions were isolated by thin-layer chromatography with hexane + diethyl ether + formic acid ( $40+10+\mathrm{I}$, by vol.) 
(Kolattukudy, 1967) as the developing solvent. The alcohol fraction was analysed as the acetate, and the acids as the methyl esters by gas chromatography.

\section{RESULTS}

\section{Growth of Micrococcus cerificans with long-chain paraffins}

Micrococcus cerificans is able to grow on medium-chain-length paraffins (hexadecane, octadecane) as the sole source of carbon (Stevenson et al. 1962; Stewart et al. 1959; Stewart \& Kallio, 1959). We have now observed that this soil organism can also utilize much longer paraffins, such as that from cabbage wax (n-nonacosane). Comparable growth was obtained with $n$-docosane (Fig. I). Since it was noted that with small inocula the organism grew slowly, larger inocula were used in the biochemical studies. In preliminary experiments the paraffin was presented to the organism coated on diatomaceous earth (Celite) since the paraffin is not readily dispersible in aqueous solution. Although it grew with this experimental technique, better growth was obtained when ultrasonic emulsification of the substrate was employed.

\section{Table I. Micrococcus cerificans: co-oxidation of n-hexadecane with $\left[{ }^{14} C\right]$ n-nonacosane $\left(C_{29}\right)$}

Mineral medium ( $100 \mathrm{ml}$ ) with $1.0 \%$ of $n$-hexadecane and $23.7 \times 10^{6}$ counts $/ \mathrm{min}$. $\left[{ }^{14} \mathrm{C}\right] n$-nonacosane were inoculated with Micrococcus cerificans and incubated for $20 \mathrm{hr}$ at $30^{\circ}$. The water layer contained radioactivity but was not analysed further.

$\begin{array}{lc}\text { Product } & \begin{array}{c}\% \text { of admini- } \\ \text { stered }{ }^{14} \mathrm{C}\end{array} \\ \text { Respiratory } \mathrm{CO}_{2} & 8.4 \\ \text { Hydrocarbon fraction } & 64.0 \\ \text { Ester fraction } & 0.8 \mathrm{I} \\ \text { Polar lipids } & 2.7 \\ \text { Wax acids } & 0.28 \\ \text { Wax alcohols } & 0.30 \\ \text { Cell residue } & 2.5\end{array}$

\section{Ester production on paraffin substrates}

The cultures were assayed for waxy ester production by thin-layer chromatography. Ester production was readily detected when hexadecane was the substrate, lesser amounts when docosane was used and none when nonacosane was the sole carbon source. To increase the chances of detecting a metabolite of nonacosane, such as a I-nonacosanol, $\left[{ }^{14} \mathrm{C}\right]$ nonacosane was presented to the organism in the presence of relatively large amounts of a readily oxidizable hydrocarbon, namely hexadecane. This co-oxidation technique with non-radioactive hexadecane and radioactive nonacosane resulted in small but significant amounts of radioactive ester being detected and isolated by the column and thin-layer chromatographic methods used (Table I). Of necessity the growth period was shortened in order to avoid extensive degradation of the presumed intermediate, nonacosanol. Gas chromatography of these esters showed that the major radioactive esters had chain lengths of 3I-34 carbon atoms. 


\section{Products formed from $\left[{ }^{14} \mathrm{C}\right]$-nonacosane by co-oxidation with hexadecane}

When the ester fraction was hydrolysed, the radioactivity was found to be equally distributed between the alcohol and acid parts (Table I). The gas-chromatographic analysis of the alcohols (as the acetate) and the acids (as methyl esters) revealed that neither had a chain length comparable to that of the substrate hydrocarbon. The

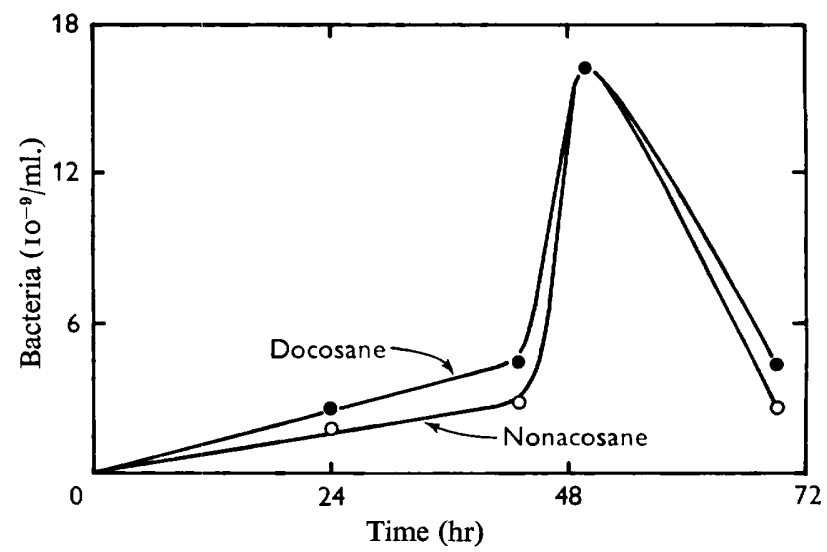

Fig. I. Growth of Micrococcus cerificans on $n$-nonacosane and $n$-docosane as sole source of carbon; $30^{\circ}$.

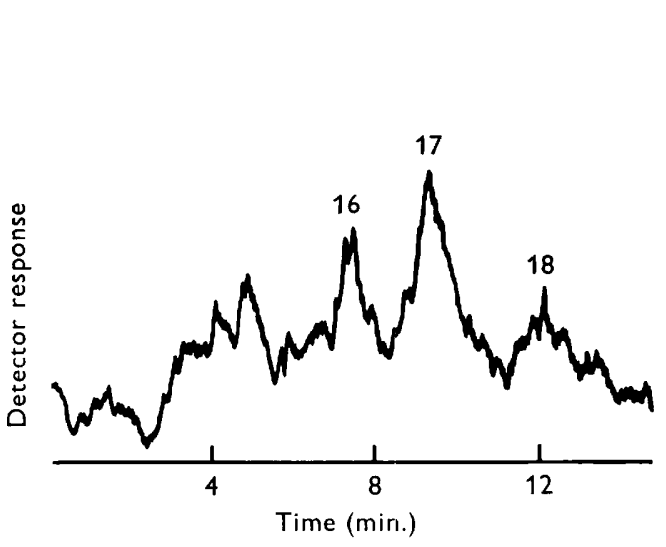

Fig. 2

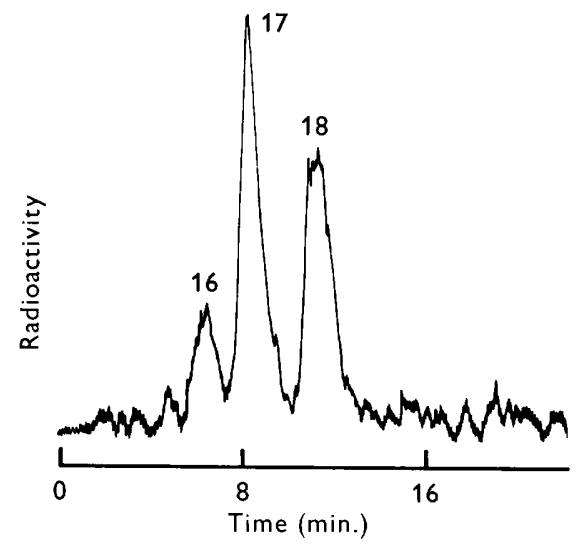

Fig. 3

Fig. 2. Radio gas-liquid chromatogram of alcohols (as acetates) derived from waxy esters produced by Micrococcus cerificans during co-oxidation of $\left[{ }^{14} \mathrm{C}\right] n$-nonacosane with $n$-hexadecane. Essentially all the mass was represented by $C_{16}$ alcohol as measured by the flame ionization detector. Experimental conditions: $\mathrm{I} 83 \mathrm{~cm}$. $(0.6 \mathrm{~cm}$. o.d.) coiled copper column, I $2 \%$ Apiezon $\mathbf{L}$ on $50-60$ mesh Anakrome A (Analabs, Hamden, Conn.), temperature of column and injector $230^{\circ}$ and $350^{\circ}$ respectively. Carrier gas was argon at $75 \mathrm{ml} . / \mathrm{min}$. Analysis on a $5 \% \mathrm{SE}-30$ column at $300^{\circ}$ did not show significantly radioactive alcohols longer than $\mathrm{C}_{18}$.

Fig. 3. Radio gas-liquid chromatogram of fatty acids (as methyl esters) derived from polar lipids produced by Micrococcus cerificans during co-oxidation of $\left[{ }^{14} \mathrm{C}\right] n$-nonacosane with $n$-hexadecane. Experimental conditions same as in Fig. 2 except the column temperature which was $220^{\circ}$. Most of the mass was represented by approximately equal quantities of saturated and unsaturated $\mathrm{C}_{16}$ acids. 
major alcohol was $\mathrm{C}_{17}$ with smaller amounts of $\mathrm{C}_{16}$ and $\mathrm{C}_{18}$ (Fig. 2). The wax acids were of similar chain lengths. The polar lipid fraction contained radioactivity several times higher than the ester fraction (Table I). The major radioactive fatty acids were $\mathrm{C}_{17}, \mathrm{C}_{18}$ and $\mathrm{C}_{16}$, in decreasing order of magnitude (Fig. 3). This distribution pattern is almost identical to that seen with the wax acids and alcohols.

\section{DISCUSSION}

A possible explanation for the absence of ester production with $n$-nonacosane is that the rate of oxidation of the very-long-chain paraffins $\left(C_{29}\right)$ is much slower than that of the medium-chain-length paraffins. Therefore, the first stable intermediate in very-long-chain oxidation (namely the alcohol) undergoes oxidative degradation as soon as it is formed. Consequently, unlike the case of the medium-length paraffins, the alcohols of the long-chain paraffins do not accumulate, and hence no ester formation occurs. If such be the case, dilution of the alcohol pool might be accomplished by

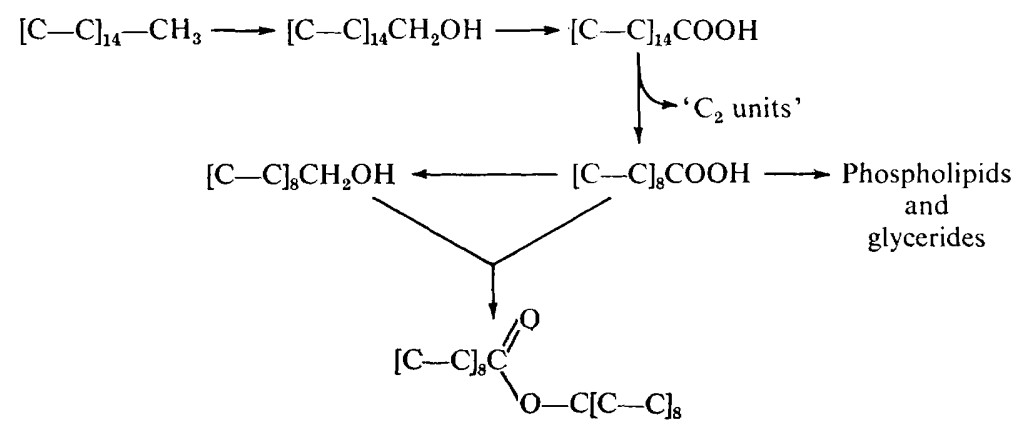

Fig. 4. Scheme of proposed metabolic fate of $n$-nonacosane in Micrococcus cerificans.

providing the organism with the readily oxidizable $C_{16}$ paraffin along with $C_{29}$ paraffin. Under these conditions sufficient nonacosanol $\left(\mathrm{C}_{29}\right)$ might accumulate for its esterification to occur. However, the absence of $\mathrm{C}_{29}$ alcohol from the ester fraction after cooxidation indicates that in spite of the dilution of the alcohol pool that must have occurred as a result of the co-oxidation, the $\mathrm{C}_{29}$ alcohol underwent preferential oxidation. The enzymes that synthesize the waxy esters may prefer the medium-chainlength alcohol $\left(\mathrm{C}_{16}\right.$ alcohol) and thus leave the $\mathrm{C}_{29}$ alcohol for oxidative degradation. However, the possibility of an oxidative attack on an internal carbon (such as $\mathrm{C}_{17}$ ) of the paraffin cannot be ruled out. The radioactive alcohols detected in the ester fraction were probably formed by reduction of fatty acids derived from the oxidation of $\mathrm{C}_{29}$ paraffin. This hypothesis is consistent with the fact that the chain lengths of the radioactive acids and alcohols were similar. Stewart et al. (1959) did find ester formation when this organism was grown on palmitic acid, although the ester production was very much less than with hexadecanol $\left(\mathrm{C}_{16}\right)$. This indicates that palmitic acid did undergo reduction to the alcohol.

These results suggest the metabolic fate of $\mathrm{C}_{29}$ paraffin with Micrococcus cerificans as depicted in Fig. 4. Although no direct evidence was obtained from the present experiments, it is likely that the end carbon of $\mathrm{C}_{29}$ paraffin would undergo oxidation 
to the corresponding alcohol presumably as described in the case of octane (Gholson, Baptist \& Coon, 1963) and hexadecane (Stewart et al. 1959; Stewart \& Kallio, 1959). This alcohol in turn is presumably oxidized to the corresponding acid which appears to undergo rapid 'chain shortening' to the level of common fatty acids of the organism $\left(\mathrm{C}_{16}-\mathrm{C}_{18}\right)$. Such a conversion could be accomplished by a $\beta$-oxidation system; but in that case the $\beta$-oxidation would have to cease at the $C_{17}$ stage. Although it is thought that $\beta$-oxidation of a fatty acid proceeds to completion, $\mathrm{C}_{18}$ acid has been shown to be converted into $\mathrm{C}_{16}$ acid in the rat by a 'leakage' in the $\beta$-oxidation system (Elovson, 1965). However, a 'chain-shortening' system (counterpart of the chainlengthening system) similar to, but not identical with the $\beta$-oxidation system, could have been responsible for the formation of $\mathrm{C}_{17}$ acid from $\mathrm{C}_{29}$ acid. If it is a 'leakage', then it must be specific enough to cause 'leakage' primarily at the $\mathrm{C}_{17}$ stage. The complete conversion of $\mathrm{C}_{29}$ acid into $\mathrm{I}_{3}$ acetate units and a propionate unit, and the resynthesis of $\mathrm{C}_{17}$ from such units, cannot be ruled out conclusively. However, the relative magnitude of radioactivity in the various metabolic products makes this unlikely. The medium-chain-length acids, primarily $C_{17}$, derived from $C_{29}$ paraffin are then incorporated mostly into phospholipids; smaller quantities undergo reduction to the alcohol which in turn is esterified. In the rat, $n$-nonacosane underwent a similar oxidative degradation, resulting in primarily $\mathrm{C}_{17}$ acid which was incorporated into phospholipids and glycerides (Kolattukudy \& Hankin, 1966).

The organism used in this study, Micrococcus cerificans, was isolated by enrichment culture with the use of hexadecane (Finnerty, Hawtrey \& Kallio, 1962) from soil. It might be possible to isolate an organism from soil which would more readily utilize, or even prefer, plant wax paraffin, if such paraffins were used in the enrichment procedures.

\section{REFERENCES}

American Public Health Association (1948). Standard Methods for the Examination of Dairy Products, 9 th ed. New York.

Champagnat, A. (1964). Proteins from petroleum fermentation-a new source of food. Impact Sci. Soc. I4, 119.

Elovson, J. (1965). Chain-shortening of stearic acid in the intact rat. Biochim. biophys. Acta 98, 36.

Finnerty, W. R., Hawtrey, E. \& Kallio, R. E. (i962). Alkane-oxidizing micrococci. Z. Allgem. Mikrobiol. 2, 169.

Folch, J., Lees, M. \& Sloane-STANley, G. H. (1957). A simple method for the isolation and purification of total lipids from animal tissues. J. biol. Chem. 226, 497.

Gholson, R. K., BAPTIST, J. N. \& CoON, M. J. (1963). Hydrocarbon oxidation by a bacterial enzyme system. II. Cofactor requirements for octanol formation from octane. Biochemistry 2, I 55.

Kolattukudy, P. E. (1965). Biosynthesis of wax in Brassica oleracea. Biochemistry 4, I 844.

Kolattukudy, P. E. (1967). Biosynthesis of paraffins in Brassica oleracea: Fatty acid elongationdecarboxylation as a plausible pathway. Phytochemistry 6, 963 .

Kolattukudy, P. E. \& Hankin, L. (1966). Metabolism of a plant wax paraffin (n-nonacosane) in the rat. J. Nutrition $90,167$.

Kuksis, A. (1964). Hydrocarbon composition of some crude and refined edible seed oils. Biochemistry 3, 1086.

Levin, E. (1963). Effects of octacosanol on chick comb growth. Proc. Soc. expt. Biol. Med. II2, 33 I.

MANGOLD, H. K. (1965). Thin layer chromatography of lipids. In Thin Layer Chromatography, a Laboratory Handbook. Ed. by E. Stahl, p. 147. New York: Academic Press Inc. 
McKenna, J. R. \& Kallio, R. E. (1965). The biology of hydrocarbons. A. Rev. Microbiol. r9, 183.

Silva-Fernandes, A. M., Baker, E. A. \& Martin, J. T. (1964). Studies on plant cuticle. VI. Isolation and fractionation of cuticular wax. Annls. appl. Biol. 53, 43.

Stevenson, F. J. (1966). Lipids in soil. J. Am. Oil Chem. Soc. 43, 203.

SteVenson, D. P., Finnerty, W. R. \& Kallio, R. E. (I962). Esters produced from $n$-Heptadecane by Micrococcus cerificans. Biochem. biophys. Res. Commun. 9, 426.

StewarT, J. R. \& Kallio, R. E. (I959). Bacterial hydrocarbon oxidation. II. Ester formation from alkanes. J. Bact. 78, 726.

Stewart, J. R., Kallio, R. E., Stevenson, D. P., Jones, A. J. \& Schissler, D. O. (1959). Bacterial hydrocarbon oxidation. I. Oxidation of $n$-Hexadecane by a gram-negative coccus. J. Bact. 78, 44I.

ZoBeLl, C. E. (1950). Assimilation of hydrocarbons by micro-organisms. Advanc. Enzymol. ro, 443. 